\title{
A desalienação do trabalhador por meio da autogestão: uma analise sob a perspectiva das três mediações de segunda ordem de Mészáros
}

\section{The worker disalienation by the self-management: an analysis under the perspective of the Mészáros's three second order mediations}

\author{
Yuri Silveira Durães ${ }^{1}$, Elcio Gustavo Benini², Gabriel Gualhanone Nemirovsky², \\ Eziel de Oliveira ${ }^{4}$
}

Resumo

\begin{abstract}
A presente pesquisa tem o objetivo de analisar como a autogestão promove a desalienação do trabalhador por meio do trabalho associado. Para orientar o estudo do processo de desalienação, são apresentados os opostos ontológicos de cada uma das mediações sociometabólicas que sustentam a estrutura do capital, segundo a interpretação de Meszáros. A aproximação empírica do objeto de estudo fundamentou-se na análise dos microdados do Sistema de Informação em Economia Solidária (SIES) fornecidos pela Secretaria Nacional de Economia Solidária (SENAES). Concluiu-se que, embora ainda seja um processo em andamento, com avanços e retrocessos, o trabalho associado é capaz de conferir ao trabalhador a propriedade do seu trabalho.
\end{abstract}

Palavras-chave: Mészáros. Autogestão. Desalienação.

\begin{abstract}
In this article we analyze how self-management is responsible for disalienate the worker through the associated work, from the perspective of Mészáros's second order mediations. The study was due to the need to understand how this process of alienation through the associated work, seeking to present the ontological opposites of each of the three Mészáros's mediations. The study was based on data provided by the National Solidarity Economy Secretariat (SENAES), through the analysis of microdata Information in Solidarity Economy System (SIES). It was concluded that, although it is still an ongoing process, with advances and setbacks, the associated work is able to give the worker the ownership of his work.
\end{abstract}

Keywords: Mészáros. Self-management. Disalienation.

\footnotetext{
1 Mestre em Administração pela Universidade Federal de Mato Grosso do Sul. Pesquisador do Grupo de Estudos e Pesquisa sobre Organizações, Trabalho e Educação - GEPOTE. E-mail: silveira.yuri@hotmail.com

2 Doutor em Educação pela Universidade Federal de Mato Grosso do Sul. Pesquisador do Grupo de Estudos e Pesquisa sobre Organizações, Trabalho e Educação - GEPOTE. E-mail: elciobenini@yahoo.com.br

3 Professor Assistente da Universidade Federal de Mato Grosso do Sul. Doutorando em Educação pelo PPGE/FFC-UNESP. Pesquisador do Grupo de Estudos e Pesquisa sobre Organizações, Trabalho e Educação - GEPOTE. Membro da Associação Brasileira de Pesquisadores da Economia Solidária - ABPES. E-mail: gabrielgnemi@gmail.com

4 Bacharel em Ciências Econômicas pela Universidade Federal de Mato Grosso do Sul. Mestrando em Administração na Universidade Federal de Mato Grosso do Sul. E-mail: eziliveira@gmail.com
} 


\section{Introdução}

A Economia Solidária tem sido considerada uma nova maneira de se produzir; como a germinação de uma forma social tanto de produção quanto de comercialização, alicerçada na autogestão que emerge das entranhas das contradições do modo de produção capitalista (DURÃES; BENINI, 2015; GAIGER, 2003; SINGER, 2002, 2003, 2007).

França Filho e Laville (2004) e Paul Singer (2007) explicam, nesse âmbito, que os trabalhadores iniciaram a construção da economia solidária nos primórdios do capitalismo industrial, como resposta à pobreza e à exploração resultantes da difusão desregulada das relações de produção que então se desenvolviam. Por sua vez, as cooperativas - talvez a forma mais emblemática e representativa deste movimento - surgem como tentativa por parte dos trabalhadores de recuperar a autonomia econômica e organizacional, mediante de novas relações sociais produtivas, mais horizontais e de controle dos trabalhadores.

É importante destacar que a luta pela construção do trabalho associado, e por conseguinte, pelas próprias condições de sobrevivência da classe trabalhadora, torna-se também uma luta contra os processos de alienação da atividade produtiva, logo uma práxis educativa que se dá com base no próprio trabalho (DAL RI; VIEITEZ, 1999; NOVAES, 2007). Portanto, se a organização típica heterogestionária é naturalmente alienante, uma vez que divide o planejamento da execução e o trabalhador dos frutos de sua atividade (MOTTA, 1986), o trabalho associado autogestionário - ainda que em sentido lógico, pois sua concretização ainda é um processo inacabado - pode ser considerado como o oposto ontológico de tal organização, ou ainda, como um instrumento de luta contrahegemônico (MORAES, 2010).
Conforme já expressou Marx, a alienação do trabalho se manifesta em aspectos diferentes: na relação do trabalhador com o produto de sua atividade, entendido como um objeto estranho; na relação do trabalhador com o ato da produção, como sua atividade de manifestação da vida singular; na relação do homem com sua espécie, como atividade da vida genérica; e por fim na relação que ocorre entre os homens sob o domínio amplo das facetas mencionadas da alienação ${ }^{5}$ (MARX, 2005).

Podemos dizer que as dimensões catalisadoras deste processo de alienação estão relacionadas com a propriedade privada dos meios de produção, o intercâmbio mercantil entre as organizações e, principalmente, a divisão hierárquica de trabalho (MARX, 2006; MARX; ENGELS, 2001; MÉSZÁROS, 2002).

Partindo dessas considerações, o objetivo geral desse artigo foi analisar como as práticas da autogestão promovem condições de desalienação do trabalhador em relação às estruturas organizacionais do capitalismo. No sentido teórico/abstrato buscou se, especificamente, contrapor os elementos ontológicos da autogestão como forma de combate as mediações sociais alienantes que fundamentam o modo de produção capitalista.

No tratamento do campo empírico e dos procedimentos metodológicos, esta pesquisa se baseia nos microdados fornecidos pelo Sistema Nacional de Informações em Economia Solidária (SIES), pertencentes à Secretaria Nacional de Economia Solidária (SENAES), do Ministério do Trabalho (MTE).

A partir deste banco de dados, buscou se identificar as estruturas e os processos da autogestão nos empreendimentos de economia solidária no Brasil, sob a lente teórica de Mészáros, à luz das mediações de segunda ordem que implicam na

\footnotetext{
5 É importante frisar que os estudos sobre a alienação e desalienação por meio do trabalho associado têm como pioneiro o professor Henrique de Novaes. Ler "O Retorno do Caracol à sua Concha: Alienação e Desalienação em Associações de Trabalhadores" (NOVAES, 2011).
} 
própria alienação. Para além de sua condição histórica de atividade subordinada aos imperativos da exploração e acumulação de capital, Mészáros (2006, p. 78) enfatiza que o trabalho corresponde a 'automediação 'ontologicamente' fudamental entre o homem e a natureza", ou seja, compreende a mediação de primeira ordem no metabolismo social.

Mészáros $(2002,2006)$ explicita quais seriam as mediações de segunda ordem, nas quais o trabalho é a força motriz e, portanto fundamental. $\mathrm{O}$ autor considera a existência de três principais mediações de segunda ordem, ou mediações da mediação fundamental - trabalho -, que se cristalizaram com o decorrer do desenvolvimento histórico do modo de produção: primeiramente a propriedade privada; o intercâmbio mercantil; e a divisão hierárquica do trabalho. Em sentido ontologicamente oposto, a presente análise propõe identificar como o processo de prática autogestionária é construído como forma de negação dessas mediações de segunda ordem, o que permite ao trabalhador restabelecer o controle e a posse do processo e resultados de sua atividade produtiva.

Para tanto, enquanto forma de exposição, buscou se abordar, primeiramente o desenvolvimento ontológico de cada uma dessas dimensões: para a dimensão patrimonial, buscamos analisar a acumulação primitiva, bem como a intermediação entre o homem e a natureza por meio da propriedade privada; para o intercâmbio, foi analisado as relações econômicas e sociais dos empreendimentos dentro do sistema capitalista; para o processo decisório, falaremos a respeito do trabalho alienante, das formas de controle científicas, da subsunção formal e real do trabalho ao capital. Desse modo, é a partir destas mediações e de suas possíveis negações que foi, sequencialmente, abordada as possibilidade e limites da própria economia solidária e dos processos que permeiam a construção da autogestão.

Tal relevância estaria justamente na proposta ontologicamente oposta da economia solidária no que diz respeito às três dimensões supracitadas, ainda que parcialmente concretizada e em processo de construção. Esta negação ocorreria a partir de: formas coletivas de propriedade dos meios de produção; formas alternativas de intercâmbio produtivo ou de circulação da riqueza social e, por fim, formas alternativas de gestão pautadas em decisões horizontais e democráticas (BENINI; BENINI; NEMIROVSKY, 2013).

Muito mais importante é compreender as contradições na produção material de nossa existência, as relações entre as forças produtivas e relações sociais de produção, enfim, as descontinuidades engendradas pela relação entre capital e trabalho. Salienta se ainda para o leitor, em vista da perspectiva aqui adotada, que procurou se analisar o objetivo de estudo a partir da perspectiva crítica de totalidade, ou seja, da inserção da economia solidária no seio das relações capitalistas, e não como uma realidade apartada ou idealizada teoricamente - como são os demais modelos de pesquisa social predominantes que se fundamentam em outras abordagens epistêmicas.

\section{Economia Solidária e Autogestão: a Luta Pelo Trabalho Associado}

É importante observar que o surgimento do movimento autogestionário foi uma resposta ao modo capitalista de produção e sua crise não só estrutural, mas também conjuntural. Esta observação é bastante importante, pois ela possibilita enxergar que o proletário chegou a um ponto onde precisava de uma alternativa para melhorar sua qualidade de vida sem afetar seus ganhos.

Uma vez que o trabalho associado, este inserido no escopo da economia solidária, busca se organiza lo de forma autogestionária. Tais experimentações apontariam para aquilo que Novaes (2007) coloca como um processo de retorno do "caracol à sua concha", uma vez que de posse dos meios de produção, o fruto do trabalho seria propriedade dos próprios trabalhadores, e o processo autogestionário, 
que pressupõe a não divisão entre concepção e execução, possibilitando o controle do processo de trabalho pelo próprio trabalhador.

Portanto, ainda que de forma incipiente, os processos de autogestão seriam capazes de anular as duas primeiras facetas da alienação, que são do trabalhador com o produto de sua atividade, e a relação do trabalhador com a própria atividade.

Traduzindo-se em palavras, Paul Singer (1998, p. 9) define a economia solidária como:

"[...] um projeto de organização sócioeconômica por princípios opostos ao do laissezfaire: em lugar da concorrência, a cooperação; em lugar da seleção darwiniana pelos mecanismos do mercado, a limitação - mas não a eliminação!, Destes mecanismos pela estruturação de relações econômicas e solidárias entre produtores e entre consumidores."

No caso dos empreendimentos solidários, decide-se através das assembleias a porcentagem que é entregue aos fundos de educação (dos sócios que possam vir a desejar formar cooperativas), aos fundos de investimento (divisíveis e indivisíveis) e o que resta é distribuído aos sócios, utilizando os critérios supracitados.

O fundo divisível pertence ao sócio e uma vez que o mesmo se desliga da cooperativa, ele tem o direito de receber sua cota. Já o fundo indivisível pertence à cooperativa como um todo. Os empreendimentos solidários possuem oito princípios, que foram imortalizados como princípios universais do cooperativismo devido ao modelo de gestão da cooperativa dos Pioneiros Equitativos de Rochdale (2002). Segundo Paul Singer, os princípios são:

$1^{\circ}$ )que nas decisões a serem tomadas cada membro teria direito a um voto, independentemente de quanto investiu na cooperativa; $2^{\circ}$ ) o número de membros da cooperativa era aberto, sendo em princípio aceito quem desejasse aderir, por isso, esse princípio é conhecido como o da "porta aberta"; $3^{\circ}$ ) sobre o capital emprestado a cooperativa pagaria uma taxa de juros fixa; $4^{\circ}$ ) as sobras seriam divididas entre os membros em proporção às compras de cada um na cooperativa; $5^{\circ}$ ) as compras na cooperativa seriam sempre à vista; $6^{\circ}$ ) os produtos vendidos pela cooperativa seriam sempre puros (isto é, não adulterados); $7^{\circ}$ ) a cooperativa se empenharia na educação dos cooperativados; $8^{\circ}$ ) a cooperativa manter-se-ia sempre neutra em questões religiosas e políticas (SINGER, 2002, p. 39-40).

Ao analisar cada um dos sete princípios, é possível entender o funcionamento dos empreendimentos solidários de forma resumida; esta vem se constituindo em um processo de organização econômica e social dos indivíduos na geração de renda, trabalho e inclusão, bem como desenvolvimento por meio da constituição de empreendimentos econômicos solidários que visam livrar o trabalhador da alienação e prepará-lo para que este atue de forma mais efetiva em seus empreendimentos, sejam eles solidários ou não. A escolha de se tornar membro de um empreendimento solidário não é só pautada em racionalidade econômica, mas também em uma questão social.

A importância da economia solidária como modo social e econômico de gestão torna-se evidente a partir dos argumentos apresentados. Quanto mais se aprofunda no tema, mais se conclui também que este modelo surgiu sob forte influência do proletário, que buscava negar o capitalismo. Tal afirmação é reforçada de maneira mais específica por Nascimento (2004, p. 2), que ainda busca conceituar de forma correlata a economia solidária e a autogestão:

A reinvenção da Economia Solidária porta em si uma espécie de ressurreição de valores que fazem parte da cultura do movimento operário: solidariedade, autogestão, autonomia, mutualismo, economia moral, e outros. Nesse sentido, Economia Solidária e Autogestão, se não são sinônimos, são termos que caminham juntos. Podemos mesmo afirmar que não há 
autogestão sem economia solidária e que não pode haver economia solidária sem autogestão. Apesar da diversidade de conceitos, podese caracterizar a Economia Solidária como "o conjunto de empreendimentos produtivos de iniciativa coletiva, com um certo grau de democracia interna e que remuneram o trabalho de forma privilegiada em relação ao capital, seja no campo ou na cidade". Por sua vez, a autogestão é mais um "ideal" de democracia econômica e gestão coletiva que caracterizam um novo modo de produção.

Tomando o pressuposto de Singer como base, é plausível afirmar que quanto mais empreendimentos, maior o mercado que pode ser abrangido, maiores suas chances de subsistência, pois estes podem atuar com trocas entre si e os sócios terão oportunidade de investir em mais de um empreendimento, o que pode acarretar em maior interesse por parte destes para lograr sucesso.

\section{O Desenvolvimento do Controle Científico do Processo de Trabalho}

Com a passagem progressiva do capitalismo concorrencial para o capitalismo monopolista, algumas mudanças significativas ocorreram nas estruturas das organizações, tanto no que diz respeitos aos aspectos patrimoniais, quanto em relação à organização e ao controle do processo de trabalho.

De fato, conforme salienta Motta (1986), tal passagem não apenas ampliou a dimensão das empresas, mas também engendrou e determinou duas separações significativas: a separação entre propriedade e administração e; o aprofundamento das formas de controle sobre o processo de trabalho e alienação do trabalhador.

Com efeito, é com o taylorismo e com o fordismo que o controle ganha revelo e é elevado a status de ciência - como pode ser observado no título do livro de Taylor, "Princípios de Administração Científica". Não obstante o carácter prescritivo-normativo, tratase de um estudo sistematizado de fragmentação e controle do trabalho - por meio de tempos e movimentos pré-determinados - cuja essência pode ser resumida na separação entre planejamento e execução; o que; por sua vez, veio a intensificar os processos de alienação do trabalhador.

Embora essa forma peculiar de controle homem-a-homem tenha sido eficaz em seu objetivo fundamental - que se resume ao aumento da produtividade e conhecimento do tempo ótimo de execução de processos de trabalho -, é com o fordismo que o controle manufatureiro do trabalho encontra nova força em seu movimento.

Conforme podemos observar nos manuais de Teoria Geral da Administração, esta avançou passando por abordagens humanísticas à abordagens tecnicistas. Com o passar do tempo, em sua busca incessante pela mais-valia, a grande empresa adotou novas formas de controle, visando tirar do trabalhador a autonomia sobre seu trabalho, transferindo o conhecimento deste para a própria organização. É interessante notar que o sentido da abordagem humanística, explicada por Motta (1986, p. 11), manifesta-se:

[...] por meio de um modelo de natureza humana, que podemos chamar de "homo social", o homem é entendido como um ser cujo comportamento não pode ser reduzido a esquemas mecanicistas, como um ser a um só tempo condicionado por demandas de ordem biológica e social. O homem é visto como amplamente movido por necessidades de segurança, aprovação social, afeto, prestígio e auto-realização. Ainda se fala sobre o grupo informal no trabalho, e a sua força sobre o indivíduo.

Os novos rumos tomados pela grande empresa levaram a uma acentuação da guerra de classes, onde o trabalhador acabou sendo distanciado, cada vez 
mais, de suas habilidades técnicas. Antunes (2000) fundamenta sua crítica explicando que o trabalho foi tomado de um modo unilateral e unitendencial, com a finalidade, nas grandes potências da época, a reduzir a autonomia do operariado. Motta (1986, p. 54) complementa:

[...] a manufatura instaurava uma nova sociedade. Essa sociedade seria intrinsecamente desfavorável à felicidade humana salvo se uma série de medidas de proteção fossem tomadas. Insistia em que a total organização social, sob o princípio do ganho e do lucro, tenderia a destruir as tradições das populações e criar um novo tipo de homem, migrante, nômade, carente de autorespeito e disciplina.

Ainda, aquele autor explica que na realidade os trabalhadores nesse caso não são somente explorados; eles são, de fato, economicamente explorados, pois são apartados do fruto de seu trabalho, e ao mesmo tempo estão alienados materialmente de sua capacidade autônoma de produzir e fruir porque o seu próprio trabalho acaba por privá-los da responsabilidade, iniciativa e liberdade e ainda os exclui da possibilidade de se apropriarem do significado político e social do seu trabalho.

Motta explica que o trabalhador, ao se deparar com esse ambiente, a princípio não se subordinaria por meio da violência, mas sim por meio de uma "“inferioridade sentida', o que paulatinamente tentariam superar com vistas a tratar com os industriais em bases iguais" (MOTTA, 1986, p. 52).

Nos EUA, diversas universidades ensinavam engenharia e administração de empresas apesar de as primeiras escolas com esse perfil nítido de "business schools" tenham sido datadas na época da primeira guerra mundial, não é demasiado diferente da história da formação de tais quadros intermediários noutros países com a economia avançada como a Alemanha e a Inglaterra (MOTTA, 1986).

A época do tecnicismo foi marcada por uma grande prosperidade, principalmente nos Estados Unidos, que contava com um mercado interno amplo, um crescimento demográfico acelerado e ainda com uma renda consideravelmente alta.

Aliado a isso, havia uma massa de trabalhadores vultosa e disponível para a formação de um exército industrial, que, adestrado, concentravase, sobretudo, no ramo automotivo de produção. $\mathrm{O}$ desenvolvimento industrial acelerado foi acompanhado de uma monopolização acentuada que permitia planejamento em longo prazo da produção, feito raro para a grande empresa.

$\mathrm{Na}$ grande empresa, segundo Motta, houve também:

[...] a grande divisão do trabalho entre os que pensam e, portanto, administram, e os que executam, e, portanto, são administrados. Cabe aos primeiros estabelecer o ritmo da produção, descrever os cargos e as funções e estudar os sistemas e métodos administrativos. Seu trabalho cria condições para o surgimento do taylorismo. Na realidade, $\mathrm{o}$ taylorismo tem por função essencial passar, para a direção capitalista, do processo de trabalho, os meios de se apropriar de todos os conhecimentos práticos, que, de fato, até então, eram monopolizados pelos operários. (MOTTA, 1986, p. 62, grifo nosso).

O taylorismo, portanto, se torna responsável por trazer uma acentuada desumanização do trabalho, pois possui uma lógica de apressamento e tal implantação traz, dentro do processo de trabalho, um caráter demasiado rotineiro e monótono. O taylorismo é responsável também por conferir alta lucratividade, por meio de baixos salários, uma vez que já não mais é necessária a qualificação da mãode-obra.

Implantou-se um processo produtivo no início do século XX, alterando a rotina do trabalho das grandes indústrias. Já nessa época, o trabalhador conquistava mais espaços em virtude do desenvolvimento de sua consciência e organização de classe. Contudo, 
a produção capitalista de mercadorias, já em sua fase imperialista, impõe com ainda mais vigor a acumulação e maximização da apropriação de valor excedente sob a forma de lucro, se desenvolve e altera a sofisticação organizacional e técnica do processo produtivo, acabando por manifestar-se sob a forma fenomênica do sistema denominado Fordismo, entendido aqui não somente unilateralmente como modelo de organização da produção de mercadorias, mas, sobretudo, como padrão de produção material e reprodução social em cujo epicentro se situa o imperativo da homogeneização das relações sociais de produção, orientado para a sustentação metabólica do complexo militar-industrial das potências econômicas.

\section{Autogestão Como Superação da Alienação: Notas Sobre a Participação Democrática nos Empreendimentos solidários}

A questão chave da autogestão é o controle sobre o processo de trabalho e a "reapropriação" dos resultados da atividade produtiva por parte da classe trabalhadora. Nesse sentido, é importante frisar que sem autogestão não há solidariedade. A busca pela gestão democrática nos empreendimentos solidários só é possível por meio de uma gestão conjunta, de um nível de participação que se caracterize como autogestão (BENINI; BENINI; 2008; SINGER, 1998, 2002, 2003). A figura 1 demonstra os níveis de participação relacionado ao controle do processo de trabalho pelos trabalhadores:

Figura 1 - Os graus e níveis de participação

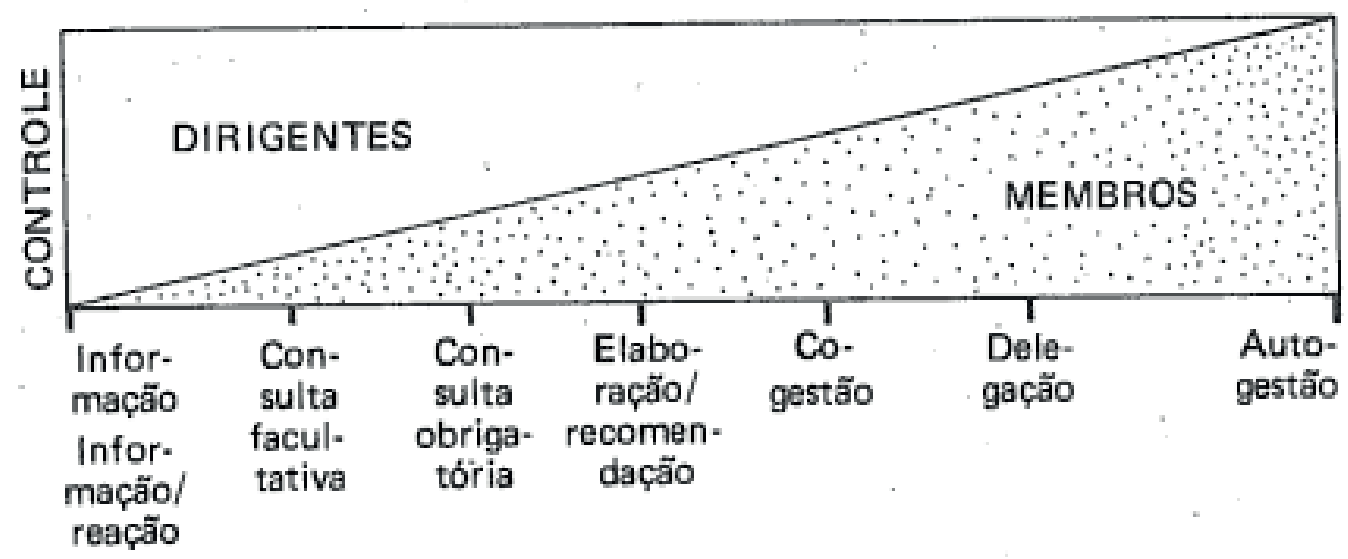

Fonte: Bordenave (1985, p. 32).

O menor grau de participação é o de informação. Os dirigentes informam os membros das organizações sobre as decisões já tomadas. Por pouco que pareça isto já constitui uma certa participação, pois não é infrequente o caso de autoridades não se darem sequer ao trabalho de informar seus subordinados. $\mathrm{Na}$ consulta facultativa a administração pode, se quiser e quando quiser, consultar os subordinados, solicitando críticas, sugestões ou dados para resolver algum problema. Quando a consulta é obrigatória os subordinados devem ser consultados em certas ocasiões, embora a decisão final pertença ainda aos diretores (BORDENAVE, 1985, p. 32-33).

A participação é explicada por Bordenave como o processo, fazer, tomar ou ter parte em algo. Já a participação social é um processo onde variadas camadas sociais apossam-se ou têm participação na gestão, usufruto ou na produção dos bens de determinada sociedade (1985). 
Ainda segundo Bordenave (1985, p. 12-13):

"Como nenhum homem é uma ilha desde suas origens o homem vive agrupado com seus iguais, a participação sempre tem acompanhado - com altos e baixos - as formas históricas que a vida social foi tomando. Entretanto, no mundo inteiro nota-se hoje uma tendência para a intensificação dos processos participativos".

Uma vez entendidos os níveis de participação e explicitado qual o nível desejável para que exista, de fato, a solidariedade presente nos empreendimentos, buscamos, por meio de uma analise dos dados fornecidos pela SENAES (BRASIL, 2013), analisar como esse processo de participação se dá na realidade dos empreendimentos no Brasil.

Na figura 2 observa-se a questão das instâncias de direção e coordenação do empreendimento. No que diz respeito ao processo decisório, foi trazido pelos dados que $35 \%$ das empresas são geridas através de assembleias gerais, $25 \%$ através de coordenação/diretoria/conselho e $20 \%$ através dos conselhos fiscais, o que indica que a maioria é, de fato, genuinamente autogerida em termos de processo decisório horizontal, enquanto $25 \%$ possui direção definida pelos sócios para a tomada de decisões mais corriqueiras.

Figura 2 - Instâncias de direção e coordenação do empreendimento

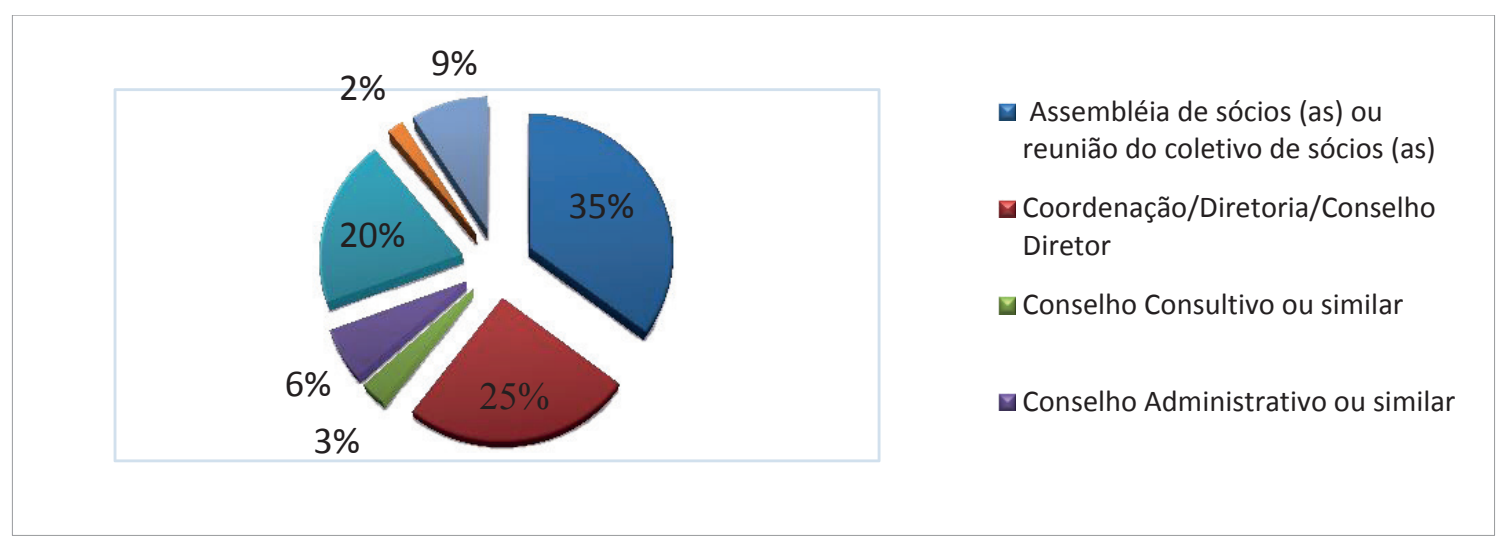

Fonte: Base de dados SIES de 2012 em: Brasil (2013).

Metade das assembleias é realizada mensalmente, enquanto $15 \%$ são realizadas bimestralmente ou trimestralmente e $11 \%$ quinzenalmente ou semanalmente, o que indica uma forte atuação dos membros para disseminação das informações e participação no processo decisório.

Das assembleias realizadas, o índice de frequência denota um ponto positivo, pois em $34 \%$ das empresas, há participação de todos os membros na assembleia, enquanto em $41 \%$ houve participação de mais de $2 / 3$ dos membros.
Essa última etapa da analise dos dados é importante, pois permite verificar se há participação dos membros na atuação dos empreendimentos solidários e a resposta foi positiva.

Lembramos ao leitor que as instâncias de direção e coordenação nos confirmam a importância de uma das mediações levantadas por Mészáros: a mediação do processo decisório. Temos aqui a confirmação de que a tomada de decisão horizontalizada é levada a sério, com altos percentuais de participação conjunta no dia-a-dia dos empreendimentos. 
Figura 3 - Periodicidade de realização da assembleia geral e/ou reunião coletiva de sócios (as) no empreendimento

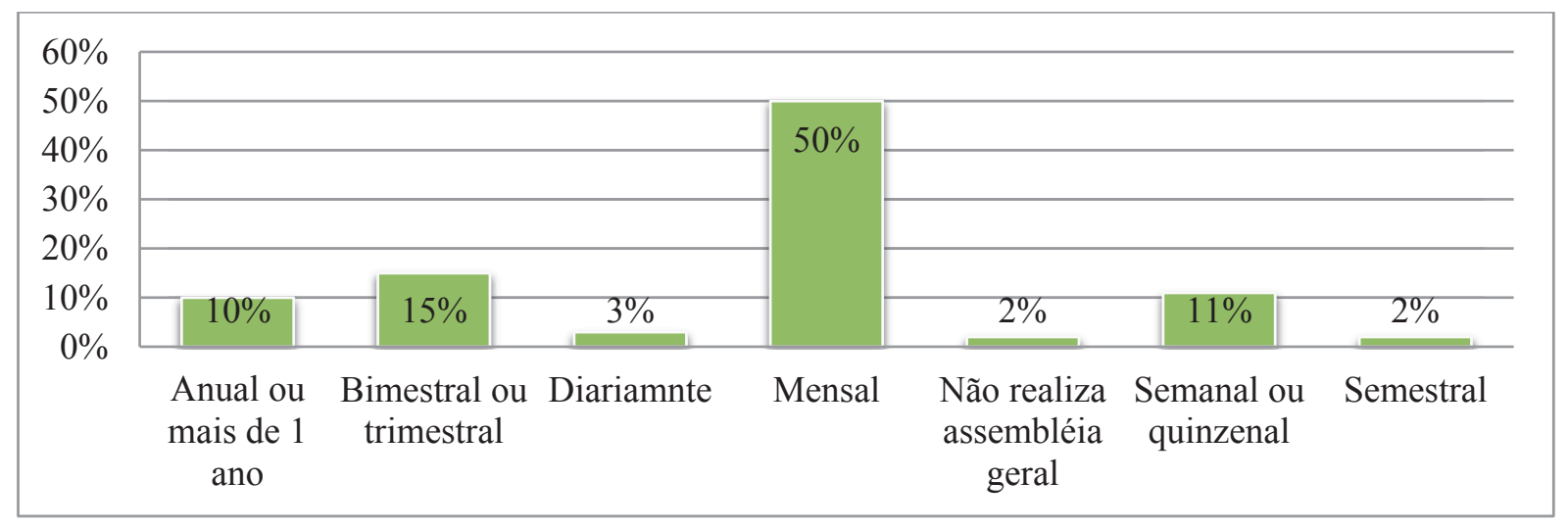

Fonte: Base de dados SIES de 2012 em: Brasil (2013).

\section{A Acumulação Primitiva E A Mediação Da Propriedade Privada}

Para se falar sobre a acumulação primitiva, processo histórico identificado na gênese do capitalismo, bem como fator essencial para o fortalecimento deste, como ferramenta de divisão da sociedade em, basicamente, duas classes cujo enfrentamento e relações sociais e econômicas fomentam a regulação do mercado capitalista, é necessário visualizar a questão da propriedade privada.

É importante também observar que as relações entre a humanidade e a natureza, em sentido dialético, cuja essência refere-se ao fato de que ao transformar a natureza o homem acaba por transformar a si próprio - (MARX, 1985) - são permeadas por mediações entre a atividade laboral fundamental do ser humano com esta natureza. Acerca disso, Mészáros (2006) explica que no modo burguês de produção de mercadorias - o capitalismo - três mediações se destacam: propriedade privada, intercâmbio e divisão de trabalho.

Com relação à mediação promovida pela propriedade privada no que diz respeito à natureza e ao homem, Benini (2010, p. 4) levanta a seguinte questão:
Para que fique claro como a propriedade privada medeia a relação fundamental entre o homem e a natureza, basta fazer a seguinte abstração/ questão: é possível processar/transformar - colocar em ação as forças produtivas do trabalho - qualquer produto da natureza, seja ele orgânico ou inorgânico, sem antes ter a sua posse? Ou ainda, sem que antes seja de convenção comum a todos, principalmente das instituições existentes, que a propriedade deste produto seja exclusivamente privada?

O modo de produção capitalista reproduz fundamentalmente a divisão da sociedade em duas classes antagônicas, entre os detentores dos meios de produção e os trabalhadores que são explorados para a acumulação do próprio capital. A partir daí, Marx explica que a acumulação primitiva é:

“[...] nada mais que o processo histórico de separação entre produtor e meio de produção. Ele aparece como "primitivo" porque constitui a préhistória do capital e do modo de produção que lhe corresponde" (MARX, 1985, p. 673).

A partir dessa divisão entre as classes, o movimento histórico e político que traz consigo a transformação dos produtores em trabalhadores assalariados aparenta, por um lado, oferecer a liberdade destes. Mas na realidade, estes 
chamados "recém-libertados" apenas se tornaram os vendedores de sua força de trabalho em virtude do fato de seus meios de produção, que lhes foram oferecidas pelas antigas instituições feudais, terem sido saqueados, e "[...]a história dessa sua expropriação está inscrita nos anais da humanidade com traços de sangue e fogo" (MARX, 1985, p. 674). Marx explica que essa expropriação pode ser entendida como acumulação primitiva, que ele define como:

[...] a alienação fraudulenta dos domínios do Estado, a ladroeira das terras comuns e a transformação da propriedade feudal e do clã em propriedade privada moderna, levada a cabo com o terrorismo implacável, figuram entre os métodos idílicos da acumulação primitiva. Conquistaram o campo para a agricultura capitalista, incorporaram as terras ao capital e proporcionaram à indústria das cidades a oferta necessária de proletários sem direitos (MARX, 1985, p.850).

Fica fácil perceber que esta suposta liberdade que é "concedida" ao trabalhador, significa representa apenas uma concepção formal, ou uma argumentação que migra de "liberdade para..." para "liberdade de...", ou seja, é uma ausência formal de restrições e/ou impedimentos institucionais, socialmente aceitos e politicamente constituídos (MONTAÑO, 2003, p. 70).

Portanto, conclui-se que o homem, visto por Locke (1994) como proprietário de si mesmo e daquilo que produz, na verdade encontra-se inserido em um sistema de subordinação ao capital; ou seja, migrou de um sistema onde sofria a coerção política para um sistema de coerção econômica. Uma vez que a chamada acumulação primitiva separou cada vez mais os trabalhadores de seus meios de produção, bem como foi responsável por acentuar a separação das duas principais classes do modo capitalista de produção (proletariado e detentores dos meios de produção), o trabalhador se vê em uma condição de "liberdade" ou "livre como pássaro" para vender sua força de trabalho e transformar os elementos da natureza em mercadorias as quais não se tornam cada vez menos acessíveis ao atendimento de suas necessidades.

\section{A Propriedade dos Meios de Produção nos Empreendimentos Econômicos Solidários: Tratando da Mediação da Propriedade Privada}

A figura 4 traz a questão da propriedade dos equipamentos (móveis, imóveis, meios de produção etc). Essa característica é pertinente, pois por meio dela podemos visualizar a estrutura patrimonial da organização.

O fato de as organizações, em sua maioria ( $76 \%$ ), serem detentoras dos equipamentos utilizados pelos empreendimentos confere uma autonomia a estes, haja vista a importante observação de que os sócios também são proprietários dos empreendimentos. Aqui vincula-se a informação à teoria de Mészáros (2002) tratando da mediação de segunda ordem, que é a mediação patrimonial. França Filho e Laville (2004) explicam que o grau de autonomia dos empreendimentos frente à totalidade capitalista é determinante da sua viabilidade, pois se trata, tanto na prática quanto na filosofia destes, de um processo de emancipação das amarras do capitalismo. 
Figura 4 - Os equipamentos dos empreendimentos

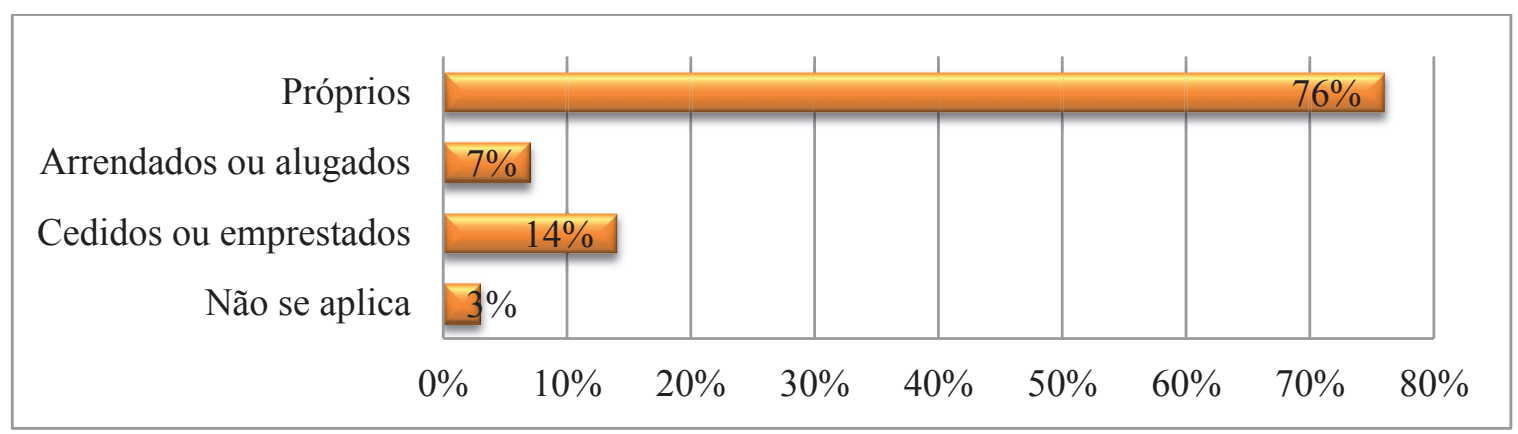

Fonte: Base de dados SIES de 2012 em: Brasil (2013).

A estrutura patrimonial dos empreendimentos apresentou-se amplamente autônoma e de propriedade dos sócios ( $48 \%$ dos empreendimentos detém a propriedade das ferramentas ou instrumentos para execução do trabalho, enquanto $36 \%$ pertencem a eles individualmente).
É necessário entender a importância dessa autonomia frente ao sistema capitalista de produção, pois uma vez livres das amarras do mecanismo darwiniano de competição (SINGER, 2002), é possível atingir a solidariedade objetivada pelos empreendimentos de forma a libertar os associados das amarras do sistema capitalista (GAIGER, 2003).

Figura 5 - Propriedade dos instrumentos, ferramentas ou equipamentos utilizados pelo EES.

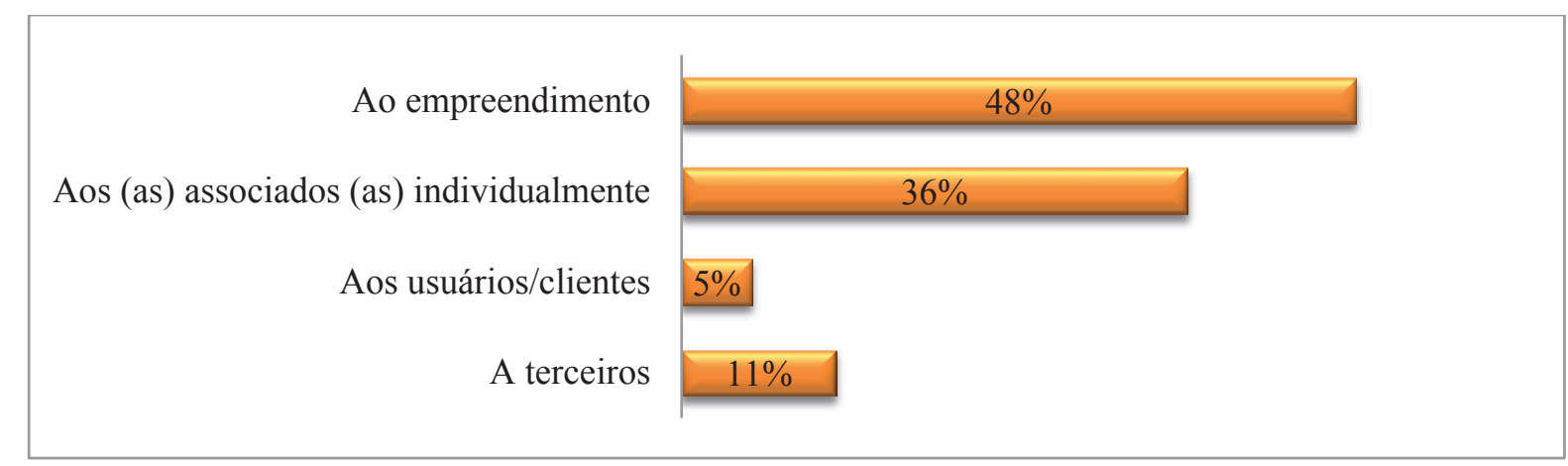

Fonte: Base de dados SIES de 2012 em: Brasil (2013).

Capitalismo, Processo de Trabalho Como Ferramenta de Criação De Mais-Valia e Subsunção do Trabalho Ao Capital

Para melhor se apreender o desenvolvimento histórico do nosso objeto de estudo - a autogestão -, ou ainda, seu desenvolvimento ontológico, é importante ter claro a dimensão a qual este tende a negar, ou a se opor, ainda que tal negação seja mais clara no sentido lógico/abstrato do que histórico/ concreto, uma vez que o trabalho associado e os processos de autogestão ocorrem inseridos na totalidade do sistema econômico vigente.

Para Romero (2005, p. 81), a premissa da produção capitalista é: 
[...] nivelar, no âmbito da circulação, todos sob um mesmo critério: possuidores de mercadorias, quer sejam dinheiro ou força de trabalho. A generalização da lei do valor para o trabalhador e para os produtos de seu trabalho, e o confronto do trabalhador com os meios de produção como propriedade de outro, para que ele, trabalhador, deve vender sua força de trabalho, são a precondição para a formação do modo de produção capitalista.

O fundamento da produção capitalista se alicerça na dinâmica de valorização que ocorre no decorrer do processo de trabalho. Ao comprar a força de trabalho, o capitalista paga pelo valor de troca este (que é seu salário) e ao inseri o trabalhador no labor fabril, visa fazer com que este produza valor excedente, ou seja, produzir um valor que supere o valor de troca (salário) pago para ele. Para Marx (1985, p. 105):

“A produção capitalista não é apenas produção de mercadorias, é essencialmente produção de mais-valia. $\mathrm{O}$ trabalhador produz não para si, mas para o capital. Não basta portanto, que produza em geral. Ele tem de produzir mais-valia. Apenas é produtivo o trabalhador que produz mais-valia para o capitalista ou serve à autovalorização do capital."

É importante salientar que aqui não se fala em alteração do processo de trabalho; se explica que dentro desta concepção, o trabalho é executado por um grupo numeroso de trabalhadores. Marx (1985, p. 441) explica mais claramente essa questão:

Mesmo não se alterando o modo de trabalho, o emprego simultâneo de um número relativamente grande de trabalhadores efetua uma revolução nas condições objetivas do processo de trabalho. Edifícios em que muitos trabalham, depósitos para matéria-prima etc., recipientes, instrumentos, aparelhos etc., que servem a muitos simultânea ou alternadamente, em suma, uma parte dos meios de produção é agora consumida em comum no processo de trabalho. Por um lado, o valor de troca de mercadorias e, portanto, também de meios de produção, não aumenta por uma exploração qualquer aumentada de seu valor de uso. Por outro lado, cresce a escala dos meios de produção utilizados em comum.

Aqui Marx fala de número, de uma quantidade de trabalhadores que estão reunidos sob o mesmo "teto" vendendo sua força de trabalho a um empregador comum, se livrando dos "grilhões da individualidade", vislumbrando a possibilidade de desenvolver a potencialidade da sua espécie.

Dessa forma o trabalho, por meio da cooperação, demanda um controle do capitalista que vislumbra um princípio organizativo por meio da ordem e da harmonia em quaisquer circunstâncias. Dentro da produção capitalista, esse tipo de organização está ligado diretamente à disciplina dos trabalhadores.

A cooperação, portanto, presente na produção capitalista passa por facetas, ou seja, ela se molda e se adapta de acordo com os moldes da produção capitalista, estando subsumida à tecnologia ou à forma de produzir que determinada época demandava. Falaremos aqui da cooperação simples, manufatureira e industrial, que por sua vez demonstram a presença da subsunção do trabalho ao capital, sob duas facetas: subsunção formal e subsunção real.

A cooperação simples, não sendo uma invenção capitalista, pode simplesmente ser entendida como uma combinação social do trabalho. Conforme pontuado por Motta (1981, p. 18) refere-se a "todas aquelas operações que não permitem por natureza a decomposição em partes, mas que, por outro lado, só pode ser realizada por muitas mãos". Portanto daí entende-se a razão da classificação do trabalho das grandes obras como caracterização de cooperação simples.

Com relação às duas formas de subsunção do trabalho, Romero (2005, p. 19, grifo nosso) explica:

A partir da análise da subsunção, Marx desenvolve os conceitos de subsunção formal 
e subsunção real. O conceito de subsunção formal designa a relação de dominação e subordinação do trabalho frente ao capital do período pré-industrial, particularmente a produção de base artesanal e/ou manufatureira. O trabalhador está subsumido ao capital na medida em que não possui meios de produção e é obrigado a se tornar um trabalhador assalariado. No entanto, esta subsunção é "apenas" formal, pois, nesse momento, a produção ainda é feita sem a introdução de máquinas. Nesse sentido, o trabalhador ainda tem um grande controle sobre o ritmo e sobre o modo de se produzir, pois detém o monopólio do conhecimento (saber-fazer) do processo e trabalho. Com isso, o aumento da exploração do trabalho, em geral, se dá pelo aumento da jornada de trabalho. $\mathbf{O}$ conceito de subsunção real designa a relação de dominação e subordinação do trabalho frente ao capital do período industrial. Nesse momento, o trabalhador passa por um processo de expropriação do seu saberfazer e cristalização desse conhecimento em um processo mecânico e objetivo (as máquinas-ferramentas). $\mathrm{O}$ trabalhador passa a não mais ter domínio completo sobre o ritmo da produção e, principalmente, passa sobre o modo de se produzir - e isso passa a ser ditado pela maquinaria, a qual subsume realmente o trabalhador. Com isso, o aumento da exploração do trabalho pode se dar igualmente pela intensificação do trabalho.

Podemos observar que Marx considera "o modo de produção especificamente capitalista" aquele onde o trabalho é realmente subsumido, por meio do desenvolvimento do trabalho social juntamente com a aplicação científica, onde os trabalhadores se tornam supérfluos e estranhos a esta relação de produção, que se torna, por conseguinte, independente deles à medida em que se autonomiza por meio do desenvolvimento da maquinaria.

\section{O Intercâmbio dos Empreendimentos Econômicos Solidários com a Totalidade Capitalista, com Os Demais Empreendimentos e com seus Associados}

Antes de iniciar a analise de dados, é importante salientar ao leitor que Paul Singer utiliza um exemplo real de atuação dentro do mercado, de forma a tornar o entendimento do funcionamento dos empreendimentos solidários mais completo, explicitando a importância do intercâmbio entre estes da seguinte maneira:

\begin{abstract}
Uma maneira de criar o novo setor de reinserção produtiva é fundar uma cooperativa de produção e de consumo, à qual se associarão a massa dos sem-trabalho e dos que sobrevivem precariamente com trabalho incerto Quanto maior o número de empresas da cooperativa, tanto melhores suas chances de sucesso. Numa grande cidade como São Paulo, em que moram centenas de milhares de pessoas que estão subocupadas ou desempregadas, o novo setor poderia conter milhares de pequenas empresas operando em ampla gama de indústrias e serviços, da confecção de roupas, alimentos, material de construção, até a reparação de automóveis e aparelhos domésticos, reformas e manutenção de edificações, creches, clínicas, escolas, etc. Atualmente é alto o desemprego entre ex-administradores de empresas, engenheiros, planejadores e outros profissionais especializados, que poderiam desde o início dar às novas pequenas empresas a base gerencial $\mathrm{e}$ técnica de que precisam. Em cidades menores, o novo setor poderia alcançar envergaduras mediante consórcio abrangendo um conjunto de municípios (SINGER, 1998, p. 123).
\end{abstract}

Agora iniciando uma analise com relação à dimensão intercambial, a figura 6 traz a questão da destinação dos produtos. Sabendo que o intercâmbio trata também da questão da criação de valor, seja ele valor de uso ou de troca, pensa-se no fim dos produtos/serviços dos empreendimentos solidários. Cuellar (2015) explica que a comercialização não é um fim, mas sim um meio para que estes 
empreendimentos sejam capazes de melhorar suas condições de subsistências e as condições de vida de seus associados. Por meio das informações, é possível observar que a comercialização é o destino da grande maioria dos empreendimentos, com $66,43 \%$ dos empreendimentos mapeados optando por esta.
A questão do autoconsumo, muito importante, sobretudo levando em consideração a agricultura familiar, corrobora com a tese de que os empreendimentos vão além da criação de valor de troca, que estes são responsáveis diretos pela subsistência dos associados.

Figura 6 - Destino dos produtos

\begin{tabular}{|l|l|l|}
\hline Destino & Quantidade & \% \\
\hline Venda & 10.726 & 66,43 \\
\hline Autoconsumo & 4.486 & $27,78 \%$ \\
\hline Troca & 786 & $4,87 \%$ \\
\hline Não se aplica & 148 & 0,92 \\
\hline Total & 16.146 & 100 \\
\hline
\end{tabular}

Fonte: Base de dados SIES de 2012 em: Brasil (2013).

A figura 7 elenca a questão da comercialização, no sentido do alcance dos produtos dos empreendimentos. Levando em consideração que o próprio mercado é desregulado em virtude da massificação da produção, a necessidade de criação de valor que gere subsistência para estes empreendimentos acaba por limitar seu raio de ação. Grande parte da venda ou troca dos produtos acontece nos limites do município, seja por meio dos centros de comercialização solidária ou centros comunitários, seja por meio do comércio municipal, que representam mais de $70 \%$ dos números. O índice de exportação de $1,53 \%$ demonstra que o intercâmbio entre os empreendimentos a nível global ainda é muito baixo

Figura 7 - A venda ou troca dos produtos acontece

\begin{tabular}{|l|c|c|}
\hline Venda ou troca & Quantidade & \% \\
\hline Comércio local ou comunitário & 7.765 & 37,85 \\
\hline Comércio municipal & 7.205 & 35,12 \\
\hline Comércio territorial ou microrregional & 2.483 & 12,10 \\
\hline Comércio estadual & 1.927 & 9,39 \\
\hline Comércio nacional & 817 & 3,98 \\
\hline Comércio externo (exportação) & 315 & 1,53 \\
\hline Total & 20.512 & 100 \\
\hline
\end{tabular}

Fonte: Base de dados SIES de 2012 em: Brasil (2013).

A figura 8 traz ainda a questão do intercâmbio, ou seja, a questão da comercialização dos produtos. Nota-se uma certa variedade e um ligeiro equilíbrio nos números, em se tratando de comercialização. As duas formas de comercialização que se destacam são a entrega direta aos clientes, $24,79 \%$ e as feiras livres com $24,72 \%$. 
As feiras de Economia Solidária constituem em uma importante estratégia de comercialização, pois além de viabilizar produção de bens e serviços, proporcionam personalização das relações entre consumidores e produtores.

Figura 8 - Principais espaços de comercialização

\begin{tabular}{|l|c|c|}
\hline Espaços de comercialização & Quantidade & \% \\
\hline Entrega direta a clientes & 5.818 & 24,79 \\
\hline Feiras livres & 5.801 & 24,72 \\
\hline Feiras e exposições eventuais/especiais & 3.549 & 15,12 \\
\hline Lojas ou espaços próprios & 3.208 & 13,67 \\
\hline Feiras de Economia Solidária e/ou agroecologia & 2.568 & 10,94 \\
\hline Espaços de venda coletivos (centrais de comercialização, CEASA) & 1.888 & 8,04 \\
\hline Outro & 639 & 2,72 \\
\hline Total & 23.471 & 100 \\
\hline
\end{tabular}

Fonte: Base de dados SIES de 2012 em: Brasil (2013).

\section{Considerações Finais}

Este trabalho surgiu com o objetivo realizar uma análise, sempre necessária de ser atualizada, dos processos em curso de autogestão a partir dos dados obtidos pelo SENAES (BRASIL, 2013), adotando como lente teórica e analítica as três mediações de segunda ordem (propriedade, intercâmbio e processo decisório), que determinam o resultado e conteúdo da relação basilar entre o homem e a natureza, por meio do trabalho, analisando como a autogestão, por meio dos princípios de mutualidade e solidariedade (re)confere aos seus associados a propriedade de seu trabalho, tanto no sentido abstrato quanto no sentido concreto, problemática considerada crucial pelo pensador contemporâneo István Mészáros.

Neste horizonte investigativo, foram selecionadas categorias que pudessem servir como auxílio para o entendimento dos processos de inserção da autogestão nos empreendimentos de economia solidária, evidenciado o conteúdo e sentido das relações sociais de produção, em ebulição no processo de luta e construção histórica da autogestão. Foram selecionadas categorias que pudessem servir como auxílio para o entendimento dos processos autogestionários nos EES, evidenciando o conteúdo e sentido das relações sociais de produção, em desenvolvimento no processo de luta e construção histórica da autogestão.

Foi realizado um levantamento bibliográfico pra tratar da questão das mediações de segunda ordem levantadas por Mészáros, conforme supracitado neste trabalho, inseridas nas relações sociais, econômicas e produtivas do sistema capitalista de produção. Ademais, buscamos, entre os dados fornecidos pelo SENAES (BRASIL, 2013), informações que nos permitissem aliar como as mediações afetam as relações dos EES com o sistema capitalista e com o homem, em primeira instância.

Para justificar a criação desse estudo foi realizado um levantamento teórico a respeito dos acontecimentos históricos que culminaram na alienação do trabalhador, catalisador para o surgimento da autogestão, sendo feita uma analise do capitalismo bem como suas características abstratas e em seguida apresentando seus opostos ontológicos (para a propriedade privada, analisamos em contraponto a acumulação primitiva; para o trabalho alienado, analisamos o trabalho emancipatório; para o processo decisório hierárquico 
verticalizado, trouxemos a autogestão "uma cabeça, um voto"). Passando pelo surgimento do capitalismo, bem como acontecimentos e processos que levaram à insatisfação do proletariado com este sistema, que motivou o início das lutas sindicais e, consequentemente, a necessidade da criação de um modo de produzir, comercializar e decidir dentro do âmbito fabril que possibilitasse ao proletário atuar de forma mais ativa na linha de produção e linha de comando sem se tornar alienado ao fruto de seu trabalho, emergindo sob a tutela de Robert Owen. (SINGER, 1998).

É importante observar que no que tange à primeira mediação, a participação, nota-se que a premissa autogestão, que é a participação em totalidade dos membros da organização no processo decisório. Os dados trazidos demonstram a característica mais positiva de nossa analise, que explicita processos que acontecem, apesar de estarem em construção, como a realização de assembleias e a participação dos membros nesta.

Enquanto caminho de negação da propriedade privada, foi apresentado a propriedade das ferramentas, equipamentos e afins que conferem ao trabalhador uma maior independência com relação à totalidade capitalista, os números também apresentam informações positivas.

Referente à dimensão intercambial - criação de valor, a destinação principal dos produtos dos empreendimentos é a venda, naturalmente, pois uma vez inseridos no modo de produção capitalista, se faz necessário a estes empreendimentos vender seus produtos para dar sequência às suas atividades, gerar renda para os sócios e subsistência para os próprios empreendimentos.

Portanto, conclui-se que a autogestão dos empreendimentos solidários é um processo concreto em construção, mas ainda em um estágio permeado de dificuldades, principalmente de ordem patrimonial-financeira e dependência mercantil. Contudo, se pudermos elencar, como Gaiger
(2003) sugere, índices de solidariedade, aqui nos deparamos com empreendimentos que, aos poucos, estão conquistando seu espaço, libertando-se das teias da dependência, conferindo autonomia e desalienando o trabalhador. Mais importante que isso: está promovendo um verdadeiro processo de resgate do conteúdo transformador do trabalho, o saber, devolvendo ao trabalhador aquilo que dele foi expropriado durante muito tempo: seu próprio trabalho.

\section{Referências}

ANTUNES, R. Os sentidos do trabalho. 2. ed. São Paulo: Boitempo, 2000.

BENINI, E. A.; BENINI, E. G. As contradições do processo de autogestão no capitalismo: funcionalidade, resistência e emancipação pela economia solidária. Revista Organização e Sociedade, Salvador, v. 17, n. 55, p. 605-619, 2010.

BENINI, E. A.; BENINI, E. G. Reforma agrária no contexto da economia solidária. Revista Nera, Presidente Prudente, Ano 11, n. 13, p. 6-15, jul./dez, 2008.

BENINI, E. A.; BENINI, E. G; NEMIROVSKY, G. G. Convergência política para a construção da autogestão global. Revista Org \& Demo, Marília, v. 14, n. 1, 2013.

BENINI, E. G. Economia solidária em questão: estudo sobre as possibilidades e limites de inserção e emancipação social no capitalismo, a partir de um estudo multicasos. 2008. Dissertação (Mestrado em Agronegócios) - Universidade Federal do Mato Grosso do Sul, Campo Grande, 2008.

O impacto da política educacional para o ensino superior a distância no trabalho docente. Tese (Doutorado em Educação) - Universidade Federal do Mato Grosso do Sul, Campo Grande, 2010.

BENINI, E. G.; DURÃES, Y. S. A qualidade da autogestão nos empreendimentos de economia solidária no Brasil: Primeiras aproximações. CONGRESSO DE PESQUISADORES DE ECONOMIA SOLIDÁRIA - CONPES, 1., 2015, São Carlos. Anais... São Carlos: UFSCar, 2015. Disponível em: <http://www.conpes. ufscar.br/wp-content/uploads/trabalhos/gt8/sessao-2/ dures_yuri_benini_elcio.pdf $>$. Acesso em: 13 mar. 2016.

BORDENAVE, J. E. D. O que é participação. São Paulo: Brasiliense, 1985. 
BRASIL. Ministério do Trabalho. Secretaria Nacional de Economia Solidária - SENAES. Boletim informativo, ano 5, ed. esp. 2013. Base de dados SIES. Disponível em: <http://portal.mte.gov.br/data/files/8A7C816A416F ABB6014173C4E66C7839/Acontece\%20SENAES $\% 20$ 2013\%20-\%20n34\%20ed\%20espercial.pdf>. Acesso em: 13 mar. 2016.

CUELLAR, T. Dependência e independência dos empreendimentos econômicos solidários para com os demais agentes econômicos no Estado de Mato Grosso do Sul. Dissertação (Mestrado em Agronegócios) Universidade Federal do Mato Grosso do Sul, Campo Grande, 2015.

DAL RI, N. M.; VIEITEZ, C. G. A economia solidária e desafio da democratização das relações de trabalho no Brasil. In: DAL RI, N. M. (Org.). A economia solidária e o desafio da democratização das relações de trabalho. São Paulo: Arte \& Ciência, 1999. p. 11 - 42.

FRANÇA FILHO, G. C.; LAVILLE, J. Economia solidária: uma abordagem internacional. Porto Alegre: Ed. da UFRGS, 2004.

GAIGER, L. A economia solidária diante do modo de produção capitalista. Caderno $C R H$, Salvador, v. 16, n. 39, p. 181-211, 2003.

LOCKE, J. Segundo tratado sobre o governo civil: ensaio sobre a origem, os limites e os fins verdadeiros do governo civil. Petrópolis: Vozes, 1994.

MARX K.; ENGELS, F. O manifesto do partido comunista. São Paulo: Boitempo, 2001.

MARX, K. Manuscritos econômico-filosóficos. São Paulo: M. Claret, 2005.

. O Capital: crítica da economia política. 2. ed. São Paulo: Nova Cultural, 1985. (Livro Primeiro, v. 1).
- O capital: crítica da economia política. São Paulo: Civilização Brasileira, 2006.

MÉSZÁROS, I. A teoria da alienação em Marx. São Paulo: Boitempo, 2006.

2002.

. Para além do capital. São Paulo: Boitempo,

MORAES, J. Self-management as a tool to organize counter-hegemony. Organização e Sociedade, Salvador, v. 17, n. 55, p. 585-604, 2010.

MOTTA, F. C. P. O que é burocracia. São Paulo: Brasiliense, 1981.

. Organização e poder. São Paulo: Atlas, 1986.

NOVAES, H. T. (Org.). O retorno do caracol à sua concha: alienação e desalienação em associações de trabalhadores. São Paulo: Expressão Popular, 2011.

NOVAES, H. T. O fetiche da tecnologia: a experiência das fábricas recuperadas. São Paulo: Expressão Popular, 2007.

ROMERO, D. Marx e a técnica: um estudo dos manuscritos de 1861-1863. São Paulo: Expressão Popular, 2005.

SINGER, P. Economia Solidária: um modo de produção e distribuição. In: SINGER, P.; SOUZA, A. (Org.). A economia solidária no Brasil. São Paulo: Contexto, 2003.

- Globalização e desemprego: diagnóstico e alternativas. São Paulo: Contexto, 1998.

Introdução a economia solidária. São Paulo:

Contexto. 2002.

The recent rebirth of the solidary economy in Brazil. In: SANTOS, Boaventura de Sousa (Org.). Another production is possible: beyond the capitalist canon. Londres: Verso, 2007. p. 1 - 42.

Recebido em: 20 ago. 2016 Aceito em: 29 maio 2017 
